\title{
REVISITANDO O ESTATUTO DO IDOSO \\ NA PERSPECTIVA DO ESTADO \\ DEMOCRÁTICO DE DIREITO
}

\section{Tiago Vieira Bomtempo}

resumo

Neste artigo pesquisou-se o contexto jurídico e social do idoso. Seu objetivo foi verificar quais avanços trouxe o Estatuto do Idoso e as críticas existentes acerca da capacidade jurídica da pessoa idosa. O estudo procurou, por meio de pesquisas bibliográficas em artigos científicos e livros com ênfase no Direito Civil, apresentar a perspectiva atual aplicada aos direitos do idoso, a partir do contexto jurídico e social presente. Após, deu-se enfoque ao envelhecimento como construção da personalidade humana, pontuando-se a observância da autonomia privada do idoso. Em seguida, mostrou-se a crítica existente acerca do envelhecimento e incapacidade jurídica, demonstrando a possível inconstitucionalidade existente no artigo 1.641, inciso II do Código Civil de 2002, ao não permitir que o idoso acima de 70 anos possa escolher qual regime de bens a ser adotado no casamento. Por fim, concluiu-se que não cabe ao Estado interferir na autonomia da pessoa idosa e que envelhecimento não é

1 Graduado em Direito. Mestre em Direito Privado pela PUC Minas. Professor universitário e membro da Comissão de Bioética e Biodireito da OAB/MG. E-mail: tiagobh15@hotmail. 

Direito, o qual deve promover a coexistência de iguais liberdades fundamentais.

palavras-chave

Estatuto do Idoso. Pessoa idosa. Autonomia. Capacidade Jurídica. Estado Democrático de Direito.

\section{Introdução}

O Direito, entendido também como fato social, visa a proteger os interesses das pessoas, de modo a buscar o equilíbrio nas relações entre os indivíduos. Entretanto, este somente encontra-se presente na medida em que fatos que mereçam sua proteção ocorram.

Assim o é inclusive na proteção das minorias, como os idosos. Foram necessárias várias manifestações e o clamor público para que tal parcela da sociedade pudesse ser tutelada por uma lei própria, o Estatuto do Idoso, a Lei n. 10.741, de 01 de outubro de $2003^{2}$.

Este microssistema jurídico, o Estatuto do Idoso, tem o fito de regular os direitos das pessoas com idade igual ou superior a 60 anos. Trata de regulamentar o artigo 230 da Constituição Federal de 1988³.

Em comentário a esta lei, Sousa discorre que:

O Estatuto do Idoso (Lei 10.741 de 01 de outubro de 2003), uma legislação contemporânea com o objetivo protetivo assistencial quanto às pessoas com idade igual ou superior a 60 (sessenta) anos, assegurou-lhes, com tutela legal ou por outros meios, todas as oportunidades e facilidades, para preservação de sua saúde física e mental e seu aperfeiçoamento moral, intelectual, espiritual e social, em condições de liberdade e dignidade [...]. (SOUSA, 2004, p. 179).

\footnotetext{
2 Além do Estatuto do Idoso, outras normas no Brasil também tutelam os idosos, como a Constituição Federal, o Código Civil, o Código Penal, a Consolidação das Leis do Trabalho, leis previdenciárias, leis processuais, a Lei da Política Nacional do Idoso (Lei 8.842/94), além de leis de no âmbito estadual e municipal.

3 Art. 230. A família, a sociedade e o Estado têm o dever de amparar as pessoas idosas, assegurando sua participação na comunidade, defendendo sua dignidade e bem-estar e garantindo-Ihes o direito à vida.

$\S 1^{\circ}$ - Os programas de amparo aos idosos serão executados preferencialmente em seus lares. $\S 2^{\circ}$ - Aos maiores de sessenta e cinco anos é garantida a gratuidade dos transportes coletivos urbanos.
} 
Consoante a esta perspectiva, buscará este artigo desenvolver o entendimento atual da autonomia do idoso no âmbito das relações privadas a partir do Estatuto do Idoso.

Todavia, considerando a ampla discussão que o tema comporta, abordar-se-á nestes estudos o envelhecimento e seu contexto jurídico; após, a dignidade da pessoa humana e os direitos de personalidade do idoso; em seguida, a crítica entre envelhecer e incapacidade jurídica; e, por fim, a inconstitucionalidade do regime de casamento de separação legal de bens.

\section{0 envelhecimento e seu contexto jurídico social}

Não se discute que com os avanços da biomedicina a expectativa de vida não só no Brasil, mas também no mundo, aumentou. A população de idosos está crescendo cada vez mais e, neste compasso, a chamada "terceira idade" já está sendo vista sob outra perspectiva, diante de vários fatores que envolvem a sociedade moderna. O termo velhice hoje abriga novos contornos que há poucas décadas nem se cogitava. Socorro explica que:

[...] tem-se que a velhice é um conceito em mudança permanente, relacionado com fatores socioeconômicos e que não são necessariamente reflexos de transformações físicas do processo de envelhecimento. Logo, pode-se afirmar que a velhice é fruto da elaboração de um discurso que tende a modificar-se de acordo com as necessidades econômicas e políticas do contexto histórico social. Por vez, esse discurso condiciona, orienta e define o comportamento das pessoas idosas e, mesmo das oportunidades que lhes são permitidas nas diversas estruturas sociais. Estes discursos são responsáveis por associar o processo biológico de uma imagem - positiva ou negativa - da velhice, atribuindo-lhe um status correspondente e que legitimará sua entrada ou exclusão em um determinado contexto histórico e social. Nesse caso, o mesmo corpo envelhecido pode ter representações totalmente distintas, o que quer dizer que a velhice, muito mais do que um conceito biológico, é uma construção social (DEBERT, 2004). Da velhice até a terceira idade, estão implicados significados que foram sendo atribuídos às pessoas envelhecidas, conforme o momento histórico, econômico e cultural. (SOCORRO, 2011, p. 29).

Neste entendimento, o Direito deve atuar no sentido de promoção dos direitos daqueles que em situações de vulnerabilidade merecem uma atenção especial. A mudança do tempo na sociedade, como o é encarada a velhice, também deve ter sua atenção jurídica, de modo a garantir autonomia e dignidade aos idosos. 
Assim, buscando trazer o conceito de idoso sob o prisma jurídico, o artigo $1^{\circ}$ do Estatuto do Idoso dispõe que: “É instituído o Estatuto do Idoso, destinado a regular os direitos assegurados às pessoas com idade igual ou superior a 60 (sessenta) anos". Desta forma, para o Direito, idoso é aquele com idade igual ou maior que 60 anos.

Entretanto, buscar definir um marco cronológico de quem é ou não idoso pode ser um tanto temerário, considerando que a lei não acompanha simultaneamente as mudanças na sociedade, pois o indivíduo de 60 anos hoje não é o mesmo de 10 anos atrás, quando o Estatuto entrou em vigor.

Sousa, citando Bobbio, esclarece que:

A velhice, segundo o mesmo autor, apresenta três sentidos: velhice censitária ou cronológica, decorrente da idade biológica vivida, que começa quando se aproxima dos oitenta anos; velhice burocrática, estabelecida pela legislação em vigor; velhice psicológica ou subjetiva, determinada pelo estado de ânimo, pelas circunstâncias históricas e sociais. (BOBBIO apud SOUSA, 2004, p. 23).

O que se pode entender é que os três sentidos de velhice (biológica, burocrática e psicológica) quando aplicados devem ser verificados consoante à dignidade da pessoa humana e aos direitos de personalidade que envolvem a pessoa idosa.

\section{Dignidade da pessoa humana e os direitos de personalidade do idoso}

A dignidade da pessoa humana é um direito fundamental e norteador da Constituição Federal de 1988, prevista no artigo 1ํㅜ inciso III $^{4}$. Conforme Farias e Rosenvald:

[...] o postulado fundamental da ordem jurídica brasileira é a dignidade humana, enfeixando todos os valores e direitos que podem ser reconhecidos à pessoa humana, englobando a afirmação de sua integridade física, psíquica e intelectual, além de garantir a sua autonomia e livre desenvolvimento da personalidade. (FARIAS; ROSENVALD, 2010, p. 124).

Princípio basilar da Constituição, a dignidade deve ser assegurada desde o nascimento até a morte do indivíduo, o que implica no envelhecimento

4 Art. $1^{\circ}$ A República Federativa do Brasil, formada pela união indissolúvel dos Estados e Municípios e do Distrito Federal, constitui-se em Estado Democrático de Direito e tem como fundamentos: III - a dignidade da pessoa humana. 
digno. Em conformidade ao texto constitucional, prevê o Estatuto do Idoso, no artigo $2^{\circ}$ que:

O idoso goza de todos os direitos fundamentais inerentes à pessoa humana, sem prejuízo da proteção integral de que trata esta Lei, assegurando-se-lhe, por lei ou por outros meios, todas as oportunidades e facilidades, para preservação de sua saúde física e mental e seu aperfeiçoamento moral, intelectual, espiritual e social, em condições de liberdade e dignidade. (BRASIL, 2003).

Não obstante, a dignidade da pessoa humana, além de ser um direito fundamental, também é um direito de personalidade que também deve ser assegurado ao idoso, tanto em sua integridade física, psíquica e intelectual, e na sua autonomia privada, dentre outros direitos que devem assegurar o livre desenvolvimento da personalidade humana.

Segundo Fiúza e Gama:

[...] a personalidade é composta de atributos, como a vida, a honra, o nome, a capacidade, o estado, o corpo físico, a psique, a dignidade, etc. Atributos são elementos componentes, em outras palavras, o material de que é composto um objeto. A pessoa humana é composta de todo esse material, ou seja, de todos esses atributos. $\bigcirc$ que se chama de direitos de personalidade são, na verdade, direitos decorrentes desses atributos, visando à proteção da pessoa humana e de sua dignidade. Essa visão moderna de que a honra, o nome, a vida, etc. integram a pessoa é fundamental para a positivação da proteção e da promoção do ser humano e para a compreensão e a garantia da igualdade, pelo menos em termos formais. (FIÚZA; GAMA, 2007, p. 14).

Neste sentido, prevê o Estatuto do Idoso no artigo 80: "O envelhecimento é um direito personalíssimo e a sua proteção um direito social, nos termos desta Lei e da legislação vigente".

Assim, entende-se que o envelhecimento também é um direito que compõe a personalidade humana e merece proteção jurídica. Ratifica referido diploma infraconstitucional o direito à vida e à saúde, além de assegurar à pessoa idosa a liberdade, o respeito e a dignidade, como pessoa humana e sujeito de direitos civis, políticos, individuais e sociais, garantidos na Constituição e na lei, previsto no artigo $9^{\circ}$ e $10^{\circ}$, respectivamente.

Em comentário a estes artigos da Lei 10.741/2003, Teixeira e Sá entendem que:

Destaca-se entre os direitos fundamentais a liberdade, cuja relevância é notória para a concretização da dignidade humana. Só pode ser digno quem pode ser livre, tendo condições psicofísicas para tal, caso contrário, a proteção que a lei 
oferece pode ser excessiva, tornando-se aprisionadora. É notório que o art. 10 do Estatuto assegura à pessoa idosa a liberdade, direito que compreende, de acordo com o seu $\$ 1^{\circ}$, os seguintes aspectos: faculdade de ir, vir e estar nos logradouros públicos e espaços comunitários, ressalvadas as restrições legais, opinião e expressão, crença e culto religioso, prática de esportes e diversões, participação na vida familiar e comunitária, na vida política, além da faculdade de buscar refúgio, auxílio e orientação. (TEIXEIRA; SÁ, 2007, p. 84).

Destaca-se que esta liberdade a ser garantida aos idosos acompanha o direito à autodeterminação e à autonomia privada, na medida em que a pessoa idosa tem o poder de decisão do que é melhor para si.

\subsection{A autonomia privada dos idosos}

No que tange a estes estudos, objetiva-se verificar como a autonomia privada é entendida no âmbito do Estatuto do Idoso e no Código Civil de 2002, com o fito de promover o livre desenvolvimento da personalidade da pessoa idosa. forma:

Amaral, citado por Teixeira e Sá, define a autonomia privada da seguinte

[...] Se quisermos tornar mais específico o tema, podemos dizer que subjetivamente, autonomia privada é o poder de alguém dar a si próprio um ordenamento jurídico e, objetivamente, o caráter próprio desse ordenamento, constituído pelo agente, em oposição ao caráter dos ordenamentos constituídos por outros. (AMARAL apud TEIXEIRA; SÁ, 2007, p. 10).

Em síntese, seria o poder de se autodeterminar, realizando escolhas conscientes e livres de qualquer vício. Nesse sentido, Diniz (2007) afirma que a autonomia privada envolve a igualdade substancial ou isonomia ao pontuar que:

Aufere-se que a autonomia pode ser entendida em sentido amplo, como uma derivação do direito à liberdade, a capacidade de um sujeito para determinar o seu comportamento individual. Contudo, no Direito Privado, este conceito é restringido. A autonomia é definida como a possibilidade de o agente decidir acerca da realização de atos ou negócios jurídicos. A autonomia privada, sob este prisma, não é absoluta. Tem de ser conciliada ao direito de outras pessoas e com valores essenciais do Estado, como a igualdade a solidariedade e a segurança. (DINIZ, 2007, p. 104).

Infere-se, portanto, que um dos objetivos do Estatuto do Idoso foi justamente tentar igualar o idoso perante os outros indivíduos, na tentativa de 
proteger o seu estado de vulnerabilidade. Daí que se falar no princípio da prioridade do idoso em que:

[...] estamos autorizados a afirmar a existência do princípio da prioridade do idoso, que determina a inserção da pessoa idosa em posição jurídica de prioridade em toda e qualquer situação em que esteja envolvida, tanto no âmbito público quanto no privado. O mais relevante é que ocorra a supressão da vulnerabilidade, para que seja restabelecida a igualdade substancial. (TEIXEIRA; PENALVA, 2009, p. 120).

Somente assim é que se pode afirmar que poderá existir a autonomia privada e o exercício de iguais liberdades pelos idosos, na concretização da dignidade da pessoa humana e dos seus direitos civis, políticos e sociais. É imperioso que os idosos demandam uma proteção especial, o que justifica terem um regramento específico, assim como existe com as crianças e adolescentes, os consumidores; enfim, indivíduos e situações nas quais merecem proteção maior do Estado.

Teixeira e Sá defendem que:

[...] o Estatuto do Idoso, Lei n.10.741/03, tem grande relevância, pois determina a proteção integral ao idoso, de modo a incentivar e resguardar o exercício de todos os seus direitos fundamentais. Ele coloca a terceira idade em pauta de discussão e reflexão, enquanto sujeitos de direito que demandam proteção especial. Referido texto regulamentou o art. 230 da Constituição Federal, que já previa a participação do idoso na comunidade, defendendo sua dignidade e bem-estar, além de garantir-Ihe o direito à vida. (TEIXEIRA; SÁ, 2007, p. 83).

Nota-se que, entretanto, esta proteção especial do Estado não significa limitar o exercício da autonomia privada do idoso, sob a alegação de este não ter pleno discernimento, pois, entendido de tal forma, o Estatuto do Idoso estaria indo na contramão do seu objetivo, o de assegurar o exercício do livre desenvolvimento da personalidade da pessoa idosa. Neste sentido, busca-se, a seguir, trazer esta discussão com um pouco mais de profundidade.

\section{Envelhecimento e (in)capacidade jurídica}

Como fase natural do processo de desenvolvimento humano, a velhice é chegada a todos em determinado momento da vida. Os cabelos vão se tornando mais ralos, a pele começa a ficar flácida, surgem as rugas, e os sentidos vão se enfraquecendo. Enfim, o corpo vai se enrijecendo. 
Entretanto, isto não quer dizer que o idoso não tenha consciência dos seus atos e discernimento nas suas escolhas. Nesta fase da vida, como fora abordado, a dignidade e a autonomia privada devem ser garantidas ao idoso.

Se, ao atingir os 60 anos de idade, este indivíduo tem direito ao trabalho, ao lazer, à educação, por que não a decidir-se por si mesmo? A vulnerabilidade e a fragilidade não implicam em incapacidade. Consoante a este entendimento, Madaleno defende que:

Disso é preciso extrair algumas importantes conclusões, no sentido de evitar que possa a idade meramente cronológica de alguma forma frear a liberdade e a autonomia da pessoa, como se as aptidões da pessoa e sua capacidade intelectiva pudessem ser determinadas apenas em razão da contagem do tempo, e como o tempo fosse por si só fator determinante para retirar do sujeito o sagrado e fundamental direito de se autodeterminar, consciente dos efeitos e da responsabilidade de sua conduta [...]. (MADALENO, 2009, p. 29).

Não existe previsão legal de que a pessoa idosa torna-se incapaz a partir do momento em que atinge 60 anos. Os artigos $3^{\circ}$ e $4^{\circ}$ do Código Civil de $2002^{5}$ não preveem esta possibilidade, nem como relativamente ou absolutamente incapazes.

Segundo Campos e Valadares:

Todo ser humano atinge a maior idade aos 18 anos completos, sendo apto a praticar atos da vida civil, só a perdendo em caso de interdição por motivo de incapacidade, devendo essa ser provada judicialmente. Devemos nos lembrar que o Código de 2002 elenca de forma taxativa, em seus artigos $3^{\circ}$ e $4^{\circ}$, as hipóteses de incapacidade, não havendo nenhuma possibilidade de considerarmos o idoso em uma delas [...]. (CAMPOS; VALADARES, 2007, p. 119).

Assim, infere-se que a capacidade é presumida e a incapacidade deve ser provada. Desta maneira, somente naqueles casos em que é perceptível que uma pessoa idosa não mais goza de suas faculdades mentais e cognitivas e não consegue se expressar é que poderia se cogitar a sua incapacidade, levando

\footnotetext{
5 Art. $3^{\circ}$ São absolutamente incapazes de exercer pessoalmente os atos da vida civil:

I - os menores de dezesseis anos; II - os que, por enfermidade ou deficiência mental, não tiverem o necessário discernimento para a prática desses atos; III - os que, mesmo por causa transitória, não puderem exprimir sua vontade.

Art. $4^{\circ}$ São incapazes, relativamente a certos atos, ou à maneira de os exercer: I - os maiores de dezesseis e menores de dezoito anos; II - os ébrios habituais, os viciados em tóxicos, e os que, por deficiência mental, tenham o discernimento reduzido; III - os excepcionais, sem desenvolvimento mental completo; IV - os pródigos. Parágrafo único. A capacidade dos índios será regulada por legislação especial.
} 
ao Judiciário para que, por meio do processo de interdição, seja lhe nomeado um curador, responsável pelos seus atos da vida civil. Neste raciocínio pontua Perlingieri:

[...] É expressão de garantia, o princípio sugerido, pelo qual somente quando as faculdades intelectivas forem gravemente comprometidas poderá, realmente, justificar-se a introdução de limites ao direito do idoso; ainda mais que se considera necessária uma verificação direta, e não presumida, dessas eventuais incapacidades. (PERLINGIERI, 2002, p. 167).

Coadunam também Campos e Valadares (2007, p. 124): "Não pode existir uma idade presumida na qual todas as pessoas se tornem incapazes, até porque a capacidade é auferida individualmente, sendo a incapacidade considerada uma exceção para o ordenamento jurídico e nunca uma presunção".

Repita-se, a vulnerabilidade e a fragilidade do idoso, o que justifica o princípio da prioridade do idoso, portanto, não serve de argumento para torná-lo incapaz para os atos da vida civil. Neste sentido, Teixeira e Sá afirmam que:

[...] o ponto central da discussão que propomos é que a fragilidade física não significa debilidade mental e que a velhice não é, por si só, incapacitante, em termos jurídicos. O envelhecer pode trazer muitas benesses, como a sabedoria advinda com a experiência, um maior conhecimento sobre a vida e sobre as pessoas. Também pode significar uma fase de maior aproveitamento da vida, com mais sossego e paz de espírito, colhendo os frutos do caminho percorrido. (TEIXEIRA; SÁ, 2007, p. 76).

Entretanto, ainda é do entendimento do Código Civil de 2002 que os idosos com 70 anos ou mais devem se casar no regime de separação legal de bens, colocando-se em discussão a constitucionalidade do referido diploma legal, objeto de estudos a seguir.

\section{5 (In)constitucionalidade do artigo 1.641, inciso $\|$ do código civil de 2002}

Diferentemente do Código Civil de 1916, que possuía um caráter patrimonialista, o atual Código Civil de 2002, tentou colocar no centro de sua disposição, a pessoa humana, sobretudo, a dignidade, para estar de acordo com a Constituição da República de 1988. Os pilares do Direito Privado: a família, a propriedade e os contratos deixaram de ter um fim patrimonial para alçar um fim social, calcada na dignidade da pessoa humana, em que preze o Estado Democrático de Direito. 
Campos e Valadares informam que:

O Código Civil de 1916 era extremamente patrimonialista e em virtude de tal característica, colocava a pessoa em segundo plano. O patrimônio era o centro de toda e qualquer relação e sua manutenção era o que determinava a constituição de uma família.

[...] com a promulgação da Constituição de 1988 houve uma verdadeira reviravolta: o patrimônio cede seu espaço para a pessoa humana, que ganha especial atenção do Estado. Enfim, a partir desse momento, a finalidade do Poder Público é garantir a dignidade da pessoa humana, sendo vedados quaisquer atos atentatórios a esse objetivo. (CAMPOS; VALADARES, 2007, p. 115-116).

Desta forma, deu-se primazia à dignidade e à liberdade para o próprio indivíduo poder decidir por si mesmo, o que não seria diferente também para a pessoa idosa, como bem pontua Diniz:

[...] o Direito Privado, nos últimos tempos, vem perdendo o seu aspecto individualista e patrimonialista, centrando-se na proteção à pessoa humana. Assim, o indivíduo, como titular de direitos fundamentais, está investido pela própria Constituição de um poder de autodeterminação de seus interesses privados. Urge, destarte, a necessidade de compatibilização entre os direitos assegurados aos idosos e o seu direito de autonomia. (DINIZ, 2007, p. 105).

Todavia, o atual Código Civil não se adequou completamente à Constituição, na medida em que limitou a autonomia privada do idoso em decidir, a partir dos 70 anos de idade, qual o regime de comunhão de bens ${ }^{6}$ a ser adotado no casamento.

Prevê o artigo 1.641, inciso II do Código Civil de 2002, com a redação dada pela Lei n. 12.344 de 2010 que: "Art. 1.641. É obrigatório o regime da separação de bens no casamento: II - da pessoa maior de 70 (setenta) anos".

Não obstante este artigo tenha sofrido modificação, passando o limite mínimo de 60 para 70 anos, referida norma ainda constitui uma violação à autonomia dos idosos, ratificando seu conteúdo discriminatório. É o que defendem Campos e Valadares (2007), ainda na vigência do limite mínimo de 60 anos:

Tendo em vista a liberdade e a autonomia privada, chegamos ao foco da discussão: o artigo 1.641, inciso II, do Código Civil limitou a autonomia privada

6 O regime de separação obrigatória de bens decorre da lei ou de pacto antenupcial. Os bens de ambos cônjuges não se comunicam, nem antes ou durante o casamento. Cada um é responsável pela administração de seus bens. 
dos idosos sem nenhuma justificativa plausível ou convincente, sendo, assim, considerado uma norma restritiva de direito, a qual devemos clamar por sua revogação.

Se o maior de 60 anos é capaz para a prática de todos os demais atos da vida civil, a vedação da liberdade de escolha do regime de bens não apresenta fundo protetivo ao indivíduo, mas sim, discriminatório, sendo uma ofensa à liberdade e uma limitação à autonomia privada, imposta exclusivamente em razão da idade. (CAMPOS; VALADARES, 2007, p. 123).

Ressalta-se novamente que a idade não deve servir de fundamento para a limitação da capacidade de alguém. Para isto, existe o meio judicial cabível, pois a capacidade é sempre presumida, e a incapacidade deve ser provada, tanto que o Estatuto do Idoso prevê em seu artigo $4^{\circ}$ que o idoso não será alvo de nenhum tipo de discriminação.

Para Teixeira e Sá:

[...] Se não existe uma idade em que a pessoa se torna incapaz - ao contrário da maioridade, em que a pessoa se torna plenamente capaz - é apenas uma sentença judicial o meio processual apto a instaurar a restrição da capacidade de alguém. Ela deverá ser fundamentada e, sobretudo, determinar os limites da incapacidade, ou seja, os atos que a pessoa não poderá praticar, conforme art. 1.772 do Código Civil. (TEIXEIRA; SÁ, 2007, p.79).

Muitos idosos com 70 anos têm completo discernimento de seus atos, inclusive o de constituírem uma família, podendo se casar em qualquer regime de bens. Não cabe ao Estado limitar a autonomia do indivíduo para a proteção de seu patrimônio, sob a alegação destes idosos serem vítimas de alguma fraude, e buscarem a proteção estatal para seu sustento. Ter mais de 70 anos não é sinônimo de prodigalidade, e ter o direito de fazer o que bem quiser com o próprio patrimônio é um exercício de autonomia, desde que se tenha discernimento dos seus atos:

Acreditamos que o legislador não buscou imputar a prodigalidade ao maior de 60 anos ao se casar, mas, sim, seus efeitos indiretos, com a finalidade de proteger o Estado de uma possível situação de miséria do idoso. Entretanto, tal idéia é incabível, pois, casando ou não, a dissipação do patrimônio é ato de liberalidade. Ademais, a prodigalidade é característica individual e psicológica, não sendo presumida por certa idade ou mesmo pela prática de um único ato, no caso, o casamento, e, sim, por atos reiterados. (CAMPOS; VALADARES, 2007, p. 121).

Ademais, além desta norma em comento, "isentar" o Estado de responsabilidade, está para proteger os herdeiros, pois, muitas vezes, na fase da vida 
em que a pessoa mais precisa de atenção e carinho, os parentes se distanciam e não desejam mais outra coisa, se não o patrimônio do idoso. Neste sentido, afirma Diniz:

Todavia, razão alguma Ihes assiste, uma vez que em razão da autonomia privada, pode qualquer indivíduo dispor de seus bens, desde que obedeça aos requisitos legais. Não é o fato de se encontrar em fase mais adiantada da vida que impossibilita ao idoso o exercício dessa autonomia, ou cria a obrigação de manutenção de seu patrimônio a fim de favorecer seus futuros herdeiros.

[...] percebe-se um desvirtuamento da teoria das incapacidades, o que se torna um instituto para a defesa de interesses patrimoniais, ao invés da proteção à pessoa do incapaz. (DINIZ, 2007, p. 86).

O contexto da família atual é preconizado na concepção de felicidade, dos indivíduos atuarem na promoção do desenvolvimento de suas personalidades uns com os outros, em uma relação de reciprocidade e alteridade. O caráter patrimonial e individualista já não se subsiste com a atual Constituição.

Conforme Madaleno (2009, p. 31): “A noção moderna de família tem sua orientação na felicidade, e essa não é marcada pelos direitos e interesses patrimoniais, mas sim pelo convívio, pelo afeto desenvolvido na vida em comum, como núcleo prevalente das relações familiares".

O entendimento atual do Judiciário, na voz do guardião da Constituição, o Supremo Tribunal Federal (STF), com a Súmula 377 foi que: “No regime de separação legal de bens, comunicam-se os adquiridos na constância do casamento".

Entretanto, o posicionamento da cúpula do Judiciário ainda não permite o exercício de iguais liberdades fundamentais, pois, se antes havia somente uma limitação legal na autonomia dos idosos com 70 anos ou mais, agora existe também uma limitação jurisprudencial, permanecendo ainda o idoso com a sua liberdade de escolha violada no regime de bens para o casamento.

Assim, verifica-se a inconstitucionalidade do artigo 1.641, incido II do Código Civil, pois, como fora explanado, causa grave violação ao exercício da autonomia privada dos idosos e de sua dignidade, o que fere, por conseguinte, o Estado Democrático de Direito, ao não permitir que os idosos possam decidir por si construírem seus individuais projetos de vida. A vida é uma construção, e o envelhecimento é o acabamento, mas que é sempre contínuo, resultado de um processo de amadurecimento, com sabedoria e reflexão, o que se pode afirmar trazer até um poder melhor de decisão para os atos da vida civil. 
Repita-se, ser idoso não é ser incompetente juridicamente, sob pena de supressão de direitos constitucionais ao não permitir o exercício de iguais liberdades fundamentais.

\section{Considerações finais}

Verificou-se os avanços trazidos pelo Estatuto do Idoso ao buscar a tutela jurídica dos idosos, pessoas vulneráveis que mereciam regramento específico próprio, daí se dizer esta lei ser um microssistema jurídico. Entretanto, não basta só a imperatividade da norma, pois há ainda muito que progredir na conscientização do respeito à autonomia e à dignidade dos idosos, direitos fundamentais que devem ser observados tanto nas relações privadas, como na família e na convivência do dia a dia, como na concretização das políticas públicas, com a atuação presente do Estado, que muitas vezes é negligente neste sentido.

Se por um lado o Estado faz pouco da sua parte, percebe-se uma movimentação maior da terceira idade na efetivação de seus direitos, saindo da postura passiva, para a ativa, buscando melhor qualidade de vida, o que implica também na promoção de um envelhecimento com dignidade e autonomia. E este só se realiza a partir de uma relação com o outro, na interação e no respeito de iguais liberdades fundamentais.

Assim, não se coaduna ao Estado Democrático de Direito presumir a incapacidade em razão da idade e deixar de dar oportunidade àquele que mesmo no fim de sua trajetória de vida almeja se casar após os 70 anos com o regime de comunhão de bens que lhe bem convier. Isto porque tal proibição viola de plano a autonomia privada e a dignidade da pessoa humana.

Dessa forma, entende-se que o Código Civil, neste aspecto, está atrasado em relação à Constituição Federal de 1988 e colide com o Estatuto do Idoso, apresentando o art. 1.641, inciso II do Código Civil de 2002, nítido caráter inconstitucional. De maneira a permitir o exercício de iguais liberdades fundamentais, urge-se pela exclusão do referido dispositivo legal no Código Civil, seja pela via judicial, com ação direta de inconstitucionalidade, seja pela via legislativa, com a proposição de projeto de lei que revogue esta norma.

Afinal, o envelhecimento faz parte da construção da personalidade, que implica também em ser livre para decidir o que é melhor para si próprio, não cabendo à lei limitar a capacidade do idoso em razão da idade. 
abstract

This article researched the legal and social context of the elderly. Its objective was to verify which advances brought the Elderly Statute and the criticisms existing on the legal capacity of the elderly. The study sought through bibliographic research with emphasis in Civil Law, to present current perspective should apply to the rights of the elderly, from context juridical and social actual. After, gave up emphasis to aging as construction of human personality, punctuating the observance of private autonomy of the elderly. Then showed up the critical existing about aging and juridical disability, demonstrating the possible existing unconstitutionality of article 1.641, section II of the 2002 Civil Code, by not allowing that the elderly over 70 years old can choose which matrimonial property regime to be adopted in marriage. Lastly, it was concluded that the state must not interfere in the autonomy the elderly person and aging is not synonymous with inability, under the Democratic State of Right, which should promote the coexistence of equal fundamental freedoms.

keywords

Elderly Statute. Elderly person. Autonomy. Juridical capacity. Democratic State of Right.

referências

BRASIL. Código Civil. Lei n’. 10.406, de 10 de janeiro de 2002. Institui o Código Civil. Diário Oficial da União, Brasília, 11 jan. 2002. Disponível em: <http://www.planalto.gov. br/ccivil_03/Leis/2002/L10406.htm>. Acesso em: 20 out. 2014.

Estatuto do Idoso. Lei n 10.741 , de $1^{\circ}$ de outubro de 2003. Dispõe sobre o Estatuto do Idoso e dá outras providências. Diário Oficial da União, Brasília, 3 out. 2003. Disponível em: <http://www.planalto.gov.br/ccivil_03/leis/2003/110.741.htm>. Acesso em: 20 out. 2014.

CAMPOS, Carolina Lopes Cançado; VALADARES, Maria Goreth Macedo. In: FIUZA, César; SÁ, Maria de Fátima Freire de; NAVES, Bruno Torquato de Oliveira (Coord.). Direito civil: Atualidades II: da autonomia privada nas situações jurídicas patrimoniais e existenciais. Belo Horizonte: Del Rey, 2007. p. 111-125. 
DINIZ, Fernanda Paula. A interpretação constitucional dos direitos dos idosos no código civil. 2007. 183 f. Dissertação (Mestrado em Direito Privado) - Programa de Pós-Graduação em Direito. Pontifícia Universidade Católica de Minas Gerais, Belo Horizonte, 2007.

FARIAS, Cristiano Chaves de; ROSENVALD, Nelson. Direito civil: teoria geral. 8. ed. Rio de Janeiro: Lumen Juris, 2010.

FIÚZA, César; GAMA, André Couto e. Teoria geral dos direitos da personalidade. In: FIUZA, César (Coord.). Curso avançado de direito civil. São Paulo: IOB Thomson, 2007. p. 09-29.

MADALENO, Rolf. Curso de direito de família. 3. ed. Rio de Janeiro: Forense, 2009.

PERLINGIERI, Pietro. Perfis do Direto Civil. 2. ed. Rio de Janeiro: Renovar, 2002.

SOCORRO, Emanuelle das Dores Figueiredo. As concepções de velhice presentes no Estatuto do idoso e nas práticas das políticas públicas destinadas aos idosos. 2011. 90 f. Dissertação (Mestrado em Psicologia) - Programa de Pós-Graduação em Psicologia, Pontifícia Universidade Católica de Minas Gerais, Belo Horizonte. 2011.

SOUSA, Ana Maria Viola. Tutela jurídica do idoso: a assistência e a convivência familiar. Campinas: Alínea, 2004.

TEIXEIRA, Ana Carolina Brochado; PENALVA, Luciana Dadalto. Princípio da prioridade do idoso no âmbito do público e do privado. In: FIUZA, César; SÁ, Maria de Fátima Freire de; NAVES, Bruno Torquato de Oliveira (Coord.). Direito civil: atualidades III: princípios jurídicos no direito privado. Belo Horizonte: Del Rey, 2009. p. 117-136.

TEIXEIRA, Ana Carolina Brochado; SÁ, Mária de Fátima Freire de. Envelhecendo com autonomia. In: FIUZA, César; SÁ, Maria de Fátima Freire de; NAVES, Bruno Torquato de Oliveira (Coord.). Direito civil: atualidades II: da autonomia privada nas situações jurídicas patrimoniais e existenciais. Belo Horizonte: Del Rey, 2007. p. 75-88. 